\title{
Das Verhältnis zwischen dem EuGH und internationalen Gerichten
}

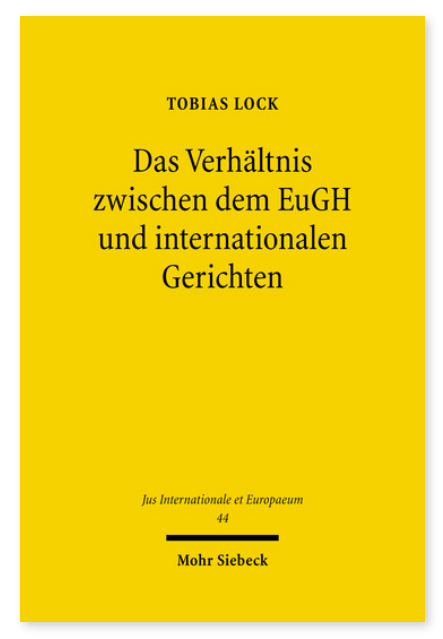

2010. XVIII, 332 Seiten. JusIntEu 44

ISBN 978-3-16-151183-7

DOI 10.1628/978-3-16-151183-7

eBook PDF 79,00€

ISBN 978-3-16-150438-9

fadengeheftete Broschur 79,00€
Die wachsende Zahl internationaler Gerichte führte bereits in der Vergangenheit zu Zuständigkeits- und Auslegungskonflikten. Wegen der zunehmenden Aktivität der Europäischen Union auf internationaler Ebene machen diese Konflikte auch vor dem EuGH nicht halt. Vor dem Hintergrund von dessen ausschließlicher Zuständigkeit, wird sein Verhältnis zu internationalen Gerichten wie dem Seegerichtshof, den Streitbeilegungsorganen der WTO oder dem EGMR untersucht. Tobias Lock erörtert, inwieweit im Völkerrecht praktizierte und diskutierte Lösungsansätze auch für den EuGH fruchtbar gemacht werden können. Die Schwerpunkte liegen auf der ausschließlichen Zuständigkeit des EuGH für Streitigkeiten zwischen Mitgliedstaaten und dabei insbesondere auf der Frage, ob andere Gerichte die ausschließliche Zuständigkeit anerkennen müssen, sowie auf dem Verhältnis des EuGH zum EGMR, vor allem nach einem Beitritt der EU zur EMRK.

Tobias Lock Geboren 1978; Studium der Rechtswissenschaft in Erlangen und Cork; 2009 Promotion; seit 2007 DAAD/Clifford Chance Lecturer in German Law am University College London.
Jetzt bestellen:

https://mohrsiebeck.com/buch/das-verhaeltnis-zwischen-dem-eugh-und-internationalen-gerichten-9783161511837?

no_cache=1

order@mohrsiebeck.com

Telefon: $+49(0) 7071-923-17$

Telefax: $+49(0) 7071-51104$ 